\title{
Analysis of 3D Virtual Worlds as Connected Knowledge Networks
}

\author{
Mehmet Firat
}

\begin{abstract}
The purpose of this study was to analyze 3D virtual worlds in terms of Connective Learning approaches with the direction of educational technology experts' opinions. Questionnaire with two sections and 6 items was used as data collection instrument. Within the context of the purpose of the study 30 participants who have 3D virtual world experience from different countries consulted through a questionnaire developed by the researcher. On this basis, features of 3D virtual worlds analyzed in terms of connected knowledge networks with the help of participant opinions. To the results of this study, the participants who have 3D virtual worlds experience strongly support that $3 \mathrm{D}$ virtual worlds and capabilities of these environments cover diversity, autonomy, interactivity, and openness features of connected knowledge networks. Also the participants who see themselves sufficient about technology usage more agree with 3D virtual worlds as connected knowledge network than who see themselves insufficient about technology usage. Some important suggestions presented as result of the research.
\end{abstract}

Index Terms-3D virtual worlds, Connectivism, Connective learning environments, connected knowledge networks.

\section{INTRODUCTION}

Rapid advances in computer and Internet technology not only affects the learning environments but also deeply influenced our views on nature of learning. Every day updated technology, exponentially increasing knowledge and communication facilities that compress the world into a global village have led the individuals to find themselves in new learning environments faster, more flexible, and high degree of communication outside of the traditional learning environments. On this grounds, high degree of using technology and communication activities as a learning activity also brought learning theories to the Digital Age [1].

Individual skills obtained from creation of connections are taking place of learning experiences that require no action and achievements anymore. And this situation makes the recognition and synthesis of connections and models as expected skills. That means learner needs to assume a new role, and this new role is the constant change and creativity [2]. These new requirements and associated, adaptive information concept emerged with social software and other emerging internet technologies have created epistemological infrastructure of a modern approach called Connectivism.

Learning and teaching through the implementation of network technologies currently in the e-learning revolution

Manuscript received September 23, 2013; revised November 23, 2013. This work was supported in part by the Anadolu University.

M. Firat is with the Department of Distance Education, Open Education Faculty, Anadolu University, Eskişehir, Turkey (e-mail: mfirat@anadolu.edu.tr). has become the latest and greatest trend of non-formal education [3] The main reason of this is given opportunities by e-learning to education. One of these most important opportunities is quickly and inexpensively accesses a wide range of learners. However, in recent times it has been understood in e-learning circles that the content is more important than how the content is intended [4]. This increases the importance of Connectivism trying to explain learning in social network structures emerged transformation of the social web or Web 2.0.

\section{A. Connectivism}

Behavioral, cognitive and constructivist learning approaches known as the traditional learning approaches engage in real learning process, not the value of learned. Thus, argue that learning and behavior only occurs in a person. For this reason, traditional learning approaches are insufficient in explanation of individual learning or just learning in today's world surrounded by virtual networks. Because learning processes was not heavily affected by computer and internet technologies yet when this theories was created [5].

When the impact of technology understood, the existing learning theories have started to fix and tried to be set in accordance with changing circumstances. But, theories become so divided and complicated that can't be able to reflect the income of defined and explained situation at the end of continuous corrections around the same point [6]. Therefore, the existing theories about learning had to be replaced by an inclusive and appropriate approach accurately reflects the relationship between theory and real. Learning in social networks gained value in this process. In this social networks gained value for learning process Siemens, (2004) aims to develop a new theoretical infrastructure for learning by his work titled "Connectivism: A Learning Theory for the Digital Age". Connectivism is a learning approach that has emerged to describe the characteristics of social, community-based contemporary learning [6].

Connectivism is an approach that claims diversity of ideas, the ability to determine the sources of information, technology, to continue the links with others, to make individual declarations, understanding the links in information and learning and skills to keep knowledge accurate and update support learning and knowledge creation [7]. However, learning is not only a mental activity, but also an act of associated networking. Learning allows the formation of new connections between old and new nodes [8]. When definitions and interpretations made by various authors on Connectivism put together, it can be said that learning and knowledge consist of nodes not contents. Accordingly, it is possible to abstract the situation of learning 
process and components in "learning ecology" as seen in Fig. 1 .

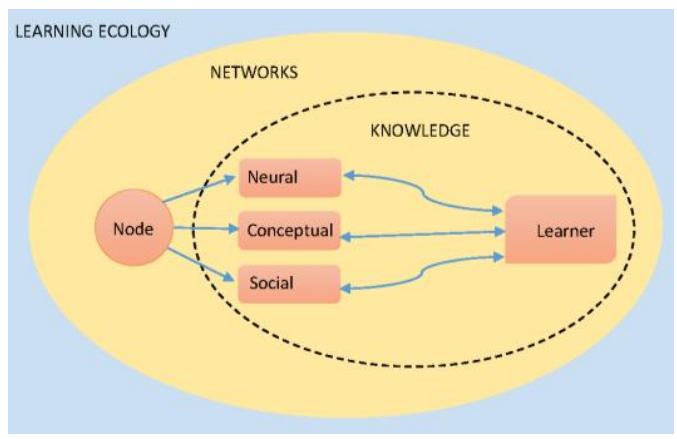

Fig. 1. Learning ecology.

Learning occurs through a variety of resources and activities. The challenge for developing a learning ecology is to define and create an environment that provide and balances the many resources and methods that learners apply to their learning. In an ecology of virtual learning environment contexts, learners inhabit a broader landscape of their own and others' making that allows them to be teachers, designers, researchers, communicators, and collaborators [9].

Connectivism claims that knowledge consists of links between nodes, not stable contents. As shown in figure 1 it is possible to define knowledge as formation of three types of connection. These connections of knowledge creation are: Neural = know-what , conceptual = know-how , and social $=$ know-who? In this case, the Connectivist learning approach refers to the establishment of new connections (neural, conceptual, and social). Similarly, networks can be defined as places where the knowledge connections occur. One of the most important concepts that make Connective learning approach unique and appropriate to the current information and communication technologies is "connective knowledge networks". According to Downes, connective knowledge networks possess four traits [10]:

1) Diversity: Diversity is about the widest possible spectrum of points of view in learning process. In other words, the important thing is the communication between learner and persons who interpret their learning in different ways.

2) Autonomy: Refers to learner's own will, they know, and the values of the decision to contribute to interactions.

3) Interactivity: Refers to accumulation of knowledge or a product of interaction between individuals.

4) Openness: Refers to the system or environment that open to interaction and accessible to others.

Connective knowledge networks form the basis of the Connectivism learning approach. These four features of connected knowledge networks can be used in order to determine the suitability of 3D virtual world applications for Connectivism learning approach.

\section{B. 3D Virtual World Applications}

3D Virtual worlds are one of the online communities. Three-dimensional (3D) virtual worlds are emerging technologies that offer unique learning opportunities for traditional and distributed education [11]. These environments often are created by using computer-aided three-dimensional simulations where individuals communicate, create and use various objects. To be a virtual world the environment must to be continuous, active, and accessible 24/7. Most of the developed 3D virtual world environments have these properties.

Some of the most popular 3D virtual world applications are Second Life, Dreamworld, There, Active Worlds and Meet Me. In 3D virtual world applications Second Life stands out with the number of users and diversity of service. Second Life (SL) is a 3D virtual world application created by U.S. company called Linden Lab and opened to service in 23 August 2003. Only in February 200838.000 avatars used this environment about 28,274,505 hours. In January 2009, 18 million people registered in this environment. By 13 August 201230500000 user sing up in Second life [12]. And there is around 12,000 to 13,000 new sign ups every day for Second Life todays.

The interaction process in Second Life 3D virtual world environments contains user-interface, interface-avatar, avatar-environment, avatar-avatar interaction. These multiple interaction create a complex structure. In these complex interaction structure also connected knowledge networks are created every moment. In order to abstract the connections in Second Life an example network graph given in Fig. 2.

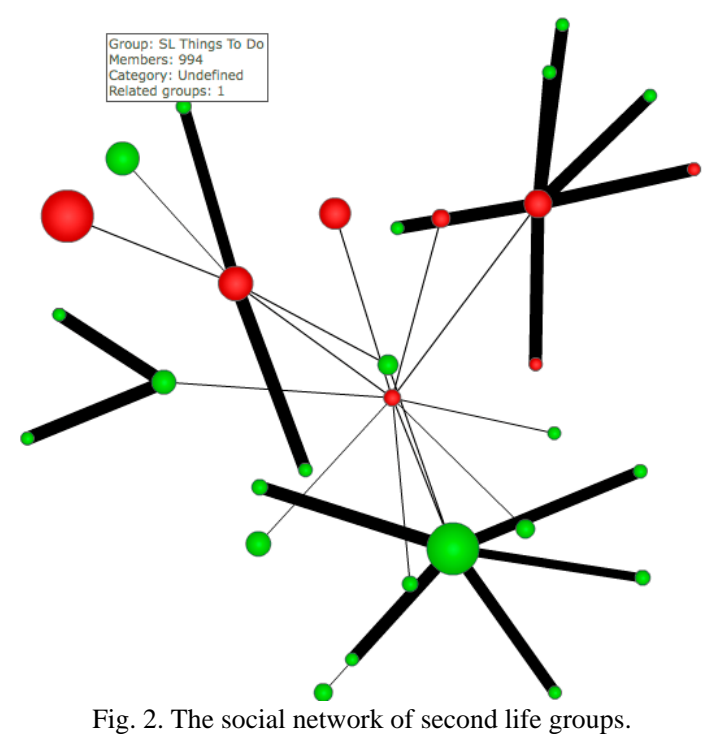

As can be seen in Fig. 2, some popular groups in Second Life have multiple connections with each other. Based on the connection potentials of $3 \mathrm{D}$ virtual worlds it is thought that instead of discontinuous, one or more text-based applications of social web, by 7 / 24 access (openness), the ever-changing content and structure (Diversity), audio-visual-written communication and interaction opportunities (Interactivity), random and real-time facilities (Autonomy) 3D virtual world applications are more suitable to use as a Connectivist learning environment. To Duncan, Miller and Jiang, 3D Virtual Worlds have great potential in teaching and learning and are a valuable contribution for collaborative learning [13].

\section{Purpose}

The purpose of this study is to analyze 3D virtual world as connected knowledge networks with the help of participant opinions who have 3D virtual world experience. 


\section{METHOD}

In this study, considering the aim of the study, single survey model, out of general survey models, was used.

\section{A. Participants}

Purposive sampling method used to determine the participants of the study. The criteria of purposive sampling were to have $3 \mathrm{D}$ virtual world experience. The participants of this study consisted of 30 participants, who have 3D virtual world experience from 7 different countries (USA, CA, UK, Turkey, Israel, Iran, and Malaysia). The participants occupation are: 4 Students (1 Post-Graduate, 2 Graduate and $1 \mathrm{PhD}), 1$ Research assistant, 8 Instructor in Educational Technology, 2 Lecturers, 2 Assistant Professors in Educational Technology, 1 Associate Professor in Educational Technology, 2 Librarian, 4 Professors (3 professor of Educational Technology, 1 professor of Math ) and 6 Instructional Designers.

\section{B. Data Collection Tools}

A questionnaire with two sections and 6 items was used as data collection instrument. While developing the questionnaire, which was used as $3 \mathrm{D}$ virtual world evaluation form; firstly item pool was formed as a result of literature review, then four field experts were conducted and the number of item was reduced to 4. These items are:

- The processes of learning in 3D virtual worlds involve the widest possible spectrum of points of view.

- The individual knower in 3D virtual worlds contributes to the interaction of their own accord, according to their own knowledge, values and decisions.

- The knowledge being produced in 3D virtual worlds is the product of an interaction between the members.

- In 3D virtual worlds there is a mechanism that allows a given perspective to be entered into the system, to be heard and interacted with by others.

For face and content validity, the questionnaire formed was presented to four field experts for their views. The questionnaire form organized in line with the experts' views was piloted with three academicians teaching at a higher education institution. Following this, the questionnaire form was finalized.

\section{Data Collection Process}

The data collection instrument with two sections and 6 items was transferred to Google Documents and sent to international e-mail lists of ITFORUM (Instructional Technology Forum) and IFETS (International Forum of Educational Technology and Society) as a discussion topic. The attachment included the purpose of the study as well as the questionnaire link for the participants willing to reach.

\section{RESULTS}

The questionnaire was made up of two parts including a total of 6 questions. In the first part of the questionnaire were one open-ended and one multiple choice item related to demographic features of participants. First question was related to the occupation of participants. Second question was related to the ability to use technology.
When the results of the first question in the first section evaluated it was seen that \%66 (20) of participants works related to Educational Technology. Participants are 8 Instructor in educational technology, 2 assistant professor in educational technology, 1 associate professor in educational technology, 3 professor of educational technology, and 6 instructional designers.

The second question of the first section was related to the participants' competence of technology usage. Results of this question show that $\% 30$ (9) of participants see themselves as insufficient in technology usage, \%70 (21) of participants see themselves as sufficient in technology usage. In this context it is possible to say that for majority of the participants have technology usage competences, works related to Educational Technology and have 3D virtual world's experiences. In the second section of the questionnaire the participant agreement with 3D virtual worlds as connected knowledge networks investigated. The agreement with the items showed below in Table I.

\section{TABLE I: AGREEMENT WITH THE ITEMS}

\begin{tabular}{llcc}
\hline \hline Items & $\mathrm{N}$ & $\mathrm{Sd}$ & $\bar{X}$ \\
\hline $\begin{array}{l}\text { The processes of learning in 3D virtual worlds } \\
\text { involve the widest possible spectrum of points of } \\
\text { view. }\end{array}$ & 30 &, 97 & 3,4 \\
$\begin{array}{l}\text { The individual knower in 3D virtual worlds } \\
\text { contributes to the interaction of their own accord, }\end{array}$ & 30 &, 78 & 3,9 \\
$\begin{array}{l}\text { according to their own knowledge, values and } \\
\text { decisions. }\end{array}$ & & & \\
$\begin{array}{l}\text { The knowledge being produced in 3D virtual worlds } \\
\text { is the product of an interaction between the } \\
\text { members. }\end{array}$ & 30 &, 96 & 3,8 \\
$\begin{array}{l}\text { In 3D virtual worlds there is a mechanism that } \\
\text { allows a given perspective to be entered into the } \\
\text { system, to be heard and interacted with by others. }\end{array}$ & 30 &, 64 & 4,0 \\
\hline \hline
\end{tabular}

The second part included 4 5-point Likert-type items. As can be seen above in Table I minimum mean is for firs item $(\bar{X}=3,4)$. All items have higher score over 3 . It means that the participants who have $3 \mathrm{D}$ virtual world experiences support 3D virtual worlds as connected knowledge networks. In these 4 5-point Likert-type items the opinions of the participants' views on 3D virtual worlds as connected knowledge network. This finding is parallel to finding of Downey, Mohler, Morris and Sanchez's study that 3D Virtual Worlds increased sense of connection with the avatars [14].

Scores of participants compared in terms of technology usage competence. But first, the results of the Kolmogorow-Smirnow Normality test applied to determine whether the frequencies of the participants' opinions on 3D virtual worlds as connected knowledge network had a normal distribution are presented in Table II below.

TABLE II: KOLMOGOROV-SMIRNOV NORMALITY TEST RESULTS

\begin{tabular}{lcccccc}
\hline \hline & $\mathrm{N}$ & $\bar{X}$ & $\mathrm{Sd}$ & $\begin{array}{c}\text { Kolmogorov-S } \\
\text { mirnov Z }\end{array}$ & $\begin{array}{c}\mathrm{p}(2 \\
\text { tailed })\end{array}$ \\
\hline $\begin{array}{l}\text { Evaluation of } \\
\text { virtual worlds as } \\
\text { connected }\end{array}$ & 30 & 3,79 &, 67 & 1,049 &, 221 \\
knowledge network & & & & & \\
\hline \hline
\end{tabular}

The results of the Kolmogorov-Smirnov test revealed that the participants' scores regarding the $3 \mathrm{D}$ virtual worlds as connected knowledge networks had normal distributions. 
$\left\lfloor D_{(30)}=1.049, p=.221>0.05\right\rfloor$ Normal distributions of the participants' scores allowed applying related parametric tests. The results of the independent samples t-test conducted to determine the degrees of the participants' agreement with the $3 \mathrm{D}$ virtual worlds as connected knowledge network with respect to the participants' technology usage competence (sufficient and insufficient) in Table III below.

TABLE III: INDEPENDENT SAMPLES $T$-TEST

\begin{tabular}{ccccccccc}
\hline \hline & Groups & $\mathrm{N}$ & $\begin{array}{c}\mathrm{F} \\
\text { (Levene) }\end{array}$ & $\bar{X}$ & $\mathrm{Sd}$ & $\mathrm{df}$ & $\mathrm{t}$ & $\mathrm{p}$ \\
\hline Participants & insufficient & 9 &, 746 & 3,36 &, 75116 & 28 & $-2,50$ &, 018 \\
& sufficient & 21 & & 3,97 &, 55286 & & & \\
\hline \hline
\end{tabular}

Independent samples $t$-test applied to determine the degrees of the participants' agreement with the $3 \mathrm{D}$ virtual worlds as connected knowledge network with respect to the participants' technology usage competence. As can be seen in Table 3, it was seen that according to the Levene $F$ test, the variances were homogenous $(p>.05)$. Thus, the t-test results could be said to be significant. As a result of the independent samples t-test conducted, it was seen that there was a significant difference between the degrees of the participants' agreement with the $3 \mathrm{D}$ virtual worlds as connected knowledge network with respect to the participants' technology usage competence $\left[t_{(30)}=2.506, p<.05\right]$.

The participants who see themselves sufficient about technology usage $(\bar{X}=3,36)$ more agree with $3 \mathrm{D}$ virtual worlds as connected knowledge network than who see themselves insufficient about technology usage $(\bar{X}=3,97)$. The reason may be cause of the participants who see themselves sufficient about technology usage have more experiences about 3D virtual worlds or the participants who see themselves insufficient about technology usage have no more idea about 3D virtual worlds as connected knowledge network.

\section{CONCLUSION}

According to Connectivism learning approach, learning occurs in constantly changing, uncertain environments rather than completely controlled environments. Many of author emphasize that wikis, blogs, video sharing sites and folksonomies as social web applications can be used in order to facilitate such learning [15], [16]. However, because of each of these applications cover only one or a few property (like pear to pear, pear to many, many to many communication) of social networks, it is thought that basic Web 2.0 applications are insufficient to create the desired Connectivist learning environments. At this point, $3 \mathrm{D}$ virtual world environments are thought to be more appropriate for characteristics of Connective learning environments of Connectivism learning approach.

Virtual world applications such as Second Life are new advanced social networks where beyond the three-dimensional visual media individuals communicate with others, different communication networks connect to each other, communication networks created [16]. In Table IV characteristic of connective networks and 3D virtual worlds investigated together.

TABLE IV: CHARACTERISTICS OF CONNECTIVE NETWORKS AND 3D VIRTUAL WORLDS

\begin{tabular}{lrl}
\hline \hline Characteristics & $\bar{X}$ & Situation in 3D Virtual Worlds \\
\hline Diversity 3,4 & $\begin{array}{l}\text { Virtual worlds have ever-changing content, } \\
\text { environment, people, and even the atmosphere } \\
\text { (Second Life). }\end{array}$ \\
Autonomy 3,9 & $\begin{array}{l}\text { In 3D Virtual Worlds events occur random and } \\
\text { simultaneously similar to real life. This feature } \\
\text { makes a 3D virtual world different from a 3D } \\
\text { virtual game. }\end{array}$ \\
Interactivity 3,8 & $\begin{array}{l}\text { In 3D Virtual Worlds high-visual-aural-written } \\
\text { communication and interaction is available. In } \\
\text { this respect 3D Virtual Worlds represent the } \\
\text { ultimate end point of technology. } \\
\text { To be a virtual world the environment must to be } \\
\text { continuous and accessible 24/7. Most of the } \\
\text { developed 3D virtual world environments have } \\
\text { these properties. In addition, avatars can affect } \\
\text { each other in these environments as similar to } \\
\text { real life. }\end{array}$ \\
\hline \hline
\end{tabular}

As shown in Table IV after the result of the analysis of the features of 3D virtual world environments it is possible to say that 3D virtual world environments strongly support Diversity, Autonomy, Interactivity, and Openness as characteristics of Connective Networks. Especially the real-world conditions, continuity, and real-time 3D visual support, and random events in 3D virtual world environments make them unique and special connective knowledge Networks.

In this study some important results revealed. To the results of this study the participants who have 3D virtual worlds experience strongly support that 3D virtual worlds and capabilities of these environments cover diversity, autonomy, and interactivity and openness features of connected knowledge networks. In other side scores of participants compared in terms of technology usage competence. The result of independent t-test results show that the participants who see themselves sufficient about technology usage more agree with $3 \mathrm{D}$ virtual worlds as connected knowledge network than who see themselves insufficient about technology usage.

Today, the scope of rapidly spreading Connectivist learning approach can be better understood with each passing day. However, integration of learning and teaching principles derived from this approach to learning environments still remains an important task. To Duncan, Miller and Jiang, researchers and educators are using these new tools in traditional and familiar ways, but the full potential of the use of Virtual Worlds in education has still to be utilized [13]. Therefore, development of suitable virtual platforms to the principles of Connectivist learning approach is vital. In the next researches the compliance of advanced social network structures such as Second Life to the principles of Connectivism approach can be examined. For this, qualitative methods such as interviews with experts or stakeholders and observations of avatars can be used.

\section{REFERENCES}

[1] G. Siemens. (January, 2009). Connectivism: A learning theory for the digital age. [Online]. Available: http://www.elearnspace.org/Articles/ connectivism .htm.

[2] M. C. Pettenati and M. E. Cigognini, "Social networking theories and tools to support connectivist learning activities," International Journal 
of Web-Based Learning and Teaching Technologies, vol. 2, no. 3, pp. 39-57, 2007.

[3] E. Welsh, C. Wanberg, K. Brown, and M. Simmering, "E-learning: emerging uses, empirical results and future directions," International Journal of Training and Development, vol. 7, no. 4, pp. 245-258, 2003.

[4] M. A. Chatti and M. Jarke, "The future of e-learning: a shift to knowledge networking and social software," International Journal of Knowledge and Learning, vol. 3, no. 4/5, pp. 404-420, 2007.

[5] I. Bessenyei, "Learning and Teaching in the Information Society. eLearning 2.0 and Connectivism, Forthcoming," in R. Pintér (ed.), Information Society. Budapest: Gondolat Új Mandátum, September, 2013

[6] G. Siemens. (January, 2009). Connectivism: Learning as network-creation. [Online]. Available: http://www.elearnspace.org/Articles/connectivism.htm.

[7] P. McGee, "Extreme learning in a virtual (world) learning environment: Who needs pedagogy anyway?" presented at ED-MEDIA World Conference on Educational Multimedia, Hypermedia \& Telecommunications, Vancouver, Canada, 2007.

[8] M. Kesim, "Connectivist Approach and Restructuring of Lifelong Learning," in Proc. EADTU Annual Conference, Poitiers France, 2008.

[9] L. Jarmon, "Homo Virtualis: Virtual Worlds, Learning, and an Ecology of Embodied Interaction," International Journal of Virtual and Personal Learning Environments, vol. 1, no. 1, pp. 1-19, 2010.

[10] S. Downes. (March, 2010). An introduction to connective knowledge. Stephen's Web. [Online]. Available: http://www.downes.ca/cgi-bin/page.cgi? post=33034.

[11] M. D. Dickey, "Three-dimensional virtual worlds and distance learning: two case studies of Active Worlds as a medium for distance education,"
British Journal of Educational Technology, vol. 36, no. 3, pp. 439-451, 2005.

[12] Lindenlab. (August, 2013). Second Life Statistical Charts. [Online]. Available: http://dwellonit.taterunino.net/sl-statistical-charts/.

[13] I. Duncan, A. Miller, and S. Jiang, "A taxonomy of virtual worlds usage in education," British Journal of Educational Technology, vol. 43, no. 6, pp. 949-964, 2012.

[14] S. Downey, J. Mohler, J. Morris, and R. Sanchez, "Learner perceptions and recall of small group discussions within 2D and 3D collaborative environments," Australasian Journal of Educational Technology, vol. 28, no. 8, pp. 1405-1419. 2012

[15] A. M. Marhan, "Connectivism: Concepts and Principles for Emerging Learning Networks," The 1st International Conference on Virtual Learning, 2006.

[16] B. Joseph, "Global kids, inc.'s best practices in using virtual worlds for education," Second Life Education Workshop, Chicago Hilton, 2007.

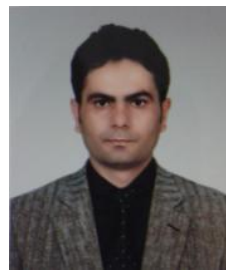

M. Firat got his $\mathrm{PhD}$ in educational technology from Anadolu University, Institute of Education, Department of Computer Education and Instructional Technology, 2012, Turkey.

His research interests are e-learning, educational multimedia and hypermedia designs, open education, virtual learning environments. He have over than 15 articles published in international indexed journals.

Dr. Firat is still member of Department of Distance Education, Open Education Faculty, Anadolu University, Turkey. 